\title{
IV
}

\section{Ecstasy and Mysticism}

\author{
By HANS HOF
}

The task I set myself in this paper is that of finding and understanding the structures in human consciousness which characterise the experience of certain kinds of ecstasy. The context in which I try to perform this task is an outline of fundamental changes in consciousness brought about by those methods of meditation which, under optimal conditions, give rise to mystical experience. I define the terms "ecstasy" and "mysticism" within the scope of this outline.

My presentation will be divided into three sections. In the first section I discuss a method of finding and interpreting structures of consciousness relevant for understanding the phenomena of ecstasy and mysticism. In the second section I present the results of an investigation based on the given method: an outline of the realms of human consciousness where different ecstatic and mystical phenomena can be placed. In the third section I offer some considerations regarding the phenomenological method that I recommend for examining the structures of consciousness of ecstasy and mysticism.

1. Concerning an experimental method in study of ecstasy and mysticism

Phenomena such as ecstasy and mysticism display both psychological and physical features. We find their defining features within the psychological sphere: what makes ecstasy ecstasy or mysticism mysticism is their psychologically describable features and not the physical ones. The physical features which are a part of these phenomena are usually regarded as secondary in relation to the psychological ones. This relation entails a methodological problem. How does one go about an experimental investigation of phenomena whose main features are to be found in subjective experience? How can one find intersubjective criteria?

16-Religious Ecstasy 
A useful approach in obtaining an answer to these questions is shown by the experiences afforded us through the so called "meditation" of the last two decades. I have in mind those forms of meditation that I call "bodycentered meditation". By these, I mean those techniques of meditation that aim at activating the nervous system and the brain without any help from ideas that have been induced into the consciousness. In Za-Zen meditation of which I have many years of experience, the physiological states of the body and thereby the states of consciousness change mainly through the adoption of an anatomically well conceived posture and a special technique of breathing.

In explaining the optimal interplay between consciousness and body which is put into action by body-centered meditation, I shall make use of a couple of theories put forward by the neurologist John Eccles and the philosopher Karl Popper in a joint work The Self and its Brain, 1978. According to their basic theory, the mental activity of the psychophysical organism is brought about by an interaction between different parts of the nervous-physiological apparatus. In another fundamental theory they claim that the mental activity brought about by interaction in the organism is to be understood as an autonomous entity called Mind or Self and which is not reducible to anything physical.

In discerning and interpreting in a meaningful way the content of the different states and realms of human consciousness which are brought about by body-centered meditation, I have been helped, most of all, by the Czech-american psychiatrist Stanislav Grof's investigations of changes in consciousness. Grof's investigations are carried out with the help of a therapy in which he combined LSD induction and conversational analysis. His experiment is based on a large number of subjects and shows unambiguously that the human psyche or consciousness displays different experiences, and that these experiences among themselves display a definite order. This order is expressed, most of all, by the fact that the maturing of an individual personality in the form of changes related to "self-experience" usually follows a certain order between the realms of consciousness. Grof's survey of the realms or levels of human consciousness is in accordance with the basic experiences of body-centered meditation. These experiences are described in a rich and extensive literature.

Another way of interpreting meaningfully the different realms of human consciousness and their mutual relations is presented in studies in which the interpretations of changes in consciousness by different traditions are compared with experience from different forms of body-centered psychotherapy and personality pedagogies. I have learnt a lot from Ken Wilber's book The Spectrum of Consciousness, 1977, which, though it sometimes 
gives a little too much rein to fantasy, gives an abundance of suggestions from which to choose critically and develop further work.

Among the approaches for understanding and explaining the states of consciousness induced by meditation is the study of the so called "bio feed back". With the help of EEG examinations, for instance, one can establish a correlation between subjective experienced states and objective measurable states in the brain's electrical activity. With this, we have at our disposal a small possibility for an intersubjective control of claims based on subjective experiences such as mysticism and ecstasy with regard to the question of the facticity of such experiences and the explanation of their origin.

\section{The structures of consciousness in ecstatic and mystical experience}

I shall try to clarify the structures of consciousness that are characteristic of ecstatic and mystical experiences by drawing a map of the changes in a person's self-experience that can be effected by a body-centered technique of meditation. One can differentiate between three types of self-experience actualised by body-centered meditation: externally conditioned self-experience, organism-centered self-experience and the experience of a transcending self. I shall consider each of these individually and examine its individual relation to ecstatic and mystical experience.

\subsection{Externally conditioned self-experiences}

This basic type of self-experience displays two subtypes: self-experience that is related to a person's experience of himself as the subject of his perceptions and the self-picture that is conditioned by the first years of upbringing in the life of a child. I shall call the former the subject of perception and the latter the psycho-dynamically conditioned self-image.

2.1.1. The subject of perception. A person's experience of himself as the subject of perception is fundamental for his self-experience. This statement is confirmed by the changes in a person's perceptual ability that are brought about by meditation. First of all, there is the visual perception which changes in two respects. I shall call one of these changes an increased immediacy in the relationship between perception and the object of perception. This involves a dispersion of, or liberation from learned patterns of interpretation and a higher degree of mental presence in experiencing the object of perception. The second change is a kind of empathy for an insight into the object which is experienced. I call it a transparent experience. In 
this the perceived object is changed; it becomes transparent; the demarcations between the object and other objects and its physical stability dissolve and give way to a more uniformly structured content of experience. In the literature, the term "disobjectivising" is sometimes used to describe this phenomenon. Both these changes involve a qualitative change in selfexperience. Transparent experience is given first place on our map of selfexperience for the location of ecstatic and mystical phenomena.

The type of mysticism that can be placed here is, in my view, identical with extrovertive mysticism in W. T. Stace's classical work Mysticism and Philosophy, 1961. He differentiates between this and introvertive mysticism which consists basically of an unio-mystica-experience, an experience of the complete oneness of the consciousness with the wholeness of everything that exists. In extrovertive mysticism consciousness of the world remains and in this is experienced a holon, a oneness of existence which fills and surrounds the universe. This can be a kind of transparent experience, i.e., a state of consciousness in which the object of consciousness-the wholeness of the physical world-becomes transparent. Such widely differing phenomena and ideas as the ones that Carlos Castaneda writes about in his books on Indian mysticism, drug-induced experiences and the Buddhistic understanding of wholeness as the interdependence of everything can be understood as interpretations of transparent experience.

What has this to do with ecstasy? What takes place in transparent experience is an expansion of consciousness, an expansion which in turn is followed by an experience of pleasure. I believe that we have introduced a class of ecstatic experience. It is distinguished by three features:

(1) the expansion of consciousness; in our example the expansion of consciousness takes place through an experience in which the object of perception becomes transparent.

(2) the expansion of consciousness is followed by an increased degree of intensity in consciousness as consciousness.

(3) the expansion and increase of intensity are followed by an experience of pleasure which absorbs or eliminates other experiences. The experience of pleasure is momentary, i.e., it is fleeting. The fact that the experience of pleasure is momentary is characteristic of the class of ecstatic experience in question here. It is precisely the relationship to time which, as will be shown, differentiates between the types of ecstasy we shall meet on our map of different types of self-experience.

\subsubsection{Psycho-dynamically conditioned self-experience. The first and basic} form of externally conditioned self-experience has been dealt with above as an experience of oneself as the subject of perception. I have called this a person's "first" self-experience because of the fact that self-experience which is vitalised or dynamised through meditation starts with a change in the subject of perception. I call it "basic" because the experience of the 
self as a subject of the activity of consciousness is central in every type of self-experience.

The next type of self-experience usually activated through the vitalising of self-experience through meditation, I have called a psycho-dynamically conditioned self-image. Similar to the subject of perception, it is externally conditioned. Self-experience here consists of an experienced image of ourselves. It is a result of the psycho-dynamic relationships which are grounded emotionally and during the first years of life between ourselves and our immediate social environment. What characterises this type of selfexperience are, primarily, the following two features:

(1) It is a relationship-experience; the image of the self is a product of the relationship-experience.

(2) The self-experience's creating relationships are social relationships.

What takes place in body-centered meditation in relation to the psychodynamically conditioned self-image is the bringing to consciousness of the relationship-experience's negative effects that have conditioned the selfimage. This bringing to consciousness often expresses itself neurotically and sometimes requires therapeutic help. I mention this for two reasons.

(1) It is necessary for a person to come to terms with difficulties in the experience of his psycho-dynamically conditioned self-image in order to reach the next type of self-experience that is actualised through meditation and which I call the autonomous self. The experience of this is in turn a necessary condition for a genuine transcendent experience or introvertive mystical experience and the ecstasy that can be found in it.

(2) The freeing of a person from difficulties in the experience of his psychodynamically conditioned self-image can trigger off an ecstasy of type (1), where expansion of consciousness is followed by increased intensity of consciousness and a momentary experience of pleasure.

\subsection{Organism conditioned self-experience: the autonomous self}

This type of self-experience differs from the two I have described above in that it does not consist of a person's experience of relationship to his environment. It is mainly made up of a person's experience that his psychophysical organism functions as a whole and in an optimal way according to its own resources. Body-centered meditation can be a part of the explanation of the origin of such self-experience: an improved interaction in the physical part of the organism is brought about through meditation and this in its turn can bring about an improved interplay between itself and consciousness.

An experience such as the autonomous self displays two forms. In one form, a person's experience of his body is central for self-experience. Here 
we have a subject-object relation between consciousness and body: the body is experienced as an objectively given place for consciousness and its activities. In the other form of autonomous self-experience the subjectobject relation is replaced by the experience that man functions purely as the subject of action: man experiences himself as functioning as an integrated psycho-physical organism. This self-experience is not concentrated in the spatially experienced body, but rather in the mental experience of oneself as a dynamic unity.

The transition to a dynamic form of autonomous self-experience has often been compared to a kind of "death-rebirth process". From my point of view, the best description of this process is given by Grof in his works on LSD-therapy: Realms of the Human Consciousness, 1975; The Human Encounter with Death, 1977, (Joan Halifax is co-author of this book) and Principles of LSD Psychotherapy, 1980. What Grof calls rebirth of the autonomous self is the overcoming of a depressive state effected by therapy. The depressive state is described in terms of "oppression" and the overcoming in terms of "consciousness' expansion". This is followed by an ecstatic experience: incresed intensity of consciousness and a positive emotional attitude.

This ecstasy is regarded as having two distinct features in addition to the features that we found in transparent experience:

(1) We found in transparent experience an expansion of consciousness and an increase in its intensity. Here we find another relation to time. The experience of pleasure is constant rather than fleeting; it "goes with time" to use an often quoted expression. The strength of intensity and the positive emotional attitude remain as a constant underlying state of consciousness. This experience, to use a theological expression, gives a character indelebilis.

(2) Another distinguishing feature in this experience of the rebirth of the self is a transcending in consciousness towards so called "transpersonal experience". This expression was introduced by the trend in existential humanistic psychology calling itself "transpersonal psychology". By transpersonal experience one is to understand experiences of a superpersonal cosmic unity, i.e., not only the experience of an ultimate dimension of wholeness and oneness in one's own organism but also that of the cosmos as a continuous wholeness.

This cosmic unity can be experienced in different ways. I shall not discuss them here. I shall group them together and call them "transcendence-experience". Common to the different forms of transcendence-experience, is the experience of the personality or self founded on something which broadens or opens itself beyond all concepts of reality, a totally deobjectivised dimension of existence. With this I have come to a third form of self-experience. 


\subsection{The transcending self}

2.3.1. Introvertive mystical experience. I shall use W. T. Stace's term "introvertive mystical experience" to describe the type of transcendenceexperience that I have discussed briefly above. Self-experience which follows introvertive mystical experience is what I call transcending selfexperience. Similar to the psycho-dynamically conditioned self-image, transcending self-experience is the experience of a relation but in this case the relation is to the content in the introvertive mystical experience.

Transcending self-experience is connected with ecstatic experience. It is distinguished by ecstasy's three distinct forms: expansion of consciousness, increased intensity and the experience of pleasure.

In the transition to a mature autonomous self-experience-I call it rebirth-an ecstasy whose intensity and positive emotions remained as a constant and underlying state of consciousness took place. This is also the case in introvertive mystical experience. In rare cases something paradoxal can take place with regard to ecstasy's remaining strengthened positive emotions: these are experienced not only as features of the mystical consciousness but also as features of the absolute unity- "a reality beyond reality" - which is the object of mystical experience. I believe that the often quoted terms "bliss" and "light" in reports about introvertive mystical experience can function as metaphysical descriptions of the phenomenon that is discussed here.

2.3.2. Ecstasy in an absolute sense. Mircea Eliade puts great emphasis on the distinction between enstasis and ekstasis in his work Le Yoga. Immortalité et Liberté, 1954. This distinction played an important role in the attempts of the scholars Louis Gardet, Louis Massignon and Jacques Cuttat to find a more adequate comparison betwen Christian and non-Christian mysticism. The distinction between enstasis and ekstasis has often been

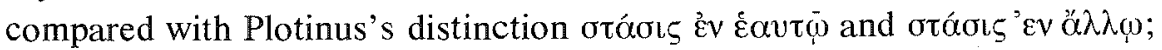
literally "a standing in oneself" and "a standing beyond oneself in an-

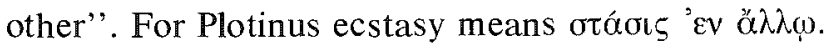

The two terms "enstasis" and "ekstasis" are understood as indicating two types of mystical experience. In the case of enstasis, the mystic does not go beyond the monistic conceived reality. According to Gardet (Mystische Erfahrungen in nichtchristlichen Ländern, 1956) for instance, the profane mystic, i.e., the mystic who does not know the Christian revelation, will, in Sufism, Hinduism and Buddhism, only reach the foundation of his soul which is conceived as one with the absolute. The being that is experienced is an "être pour soi". According to Gardet the experience of 
the great Christian mystics is different: their consciousness is led to God's being which is an ens a se, absolutely distinct from man and his consciousness. Only through the Christian experience of grace is it possible, accord-

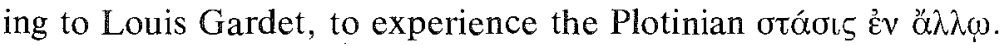

The French jesuit Joseph Marechal, who inspired Karl Rahner and others towards a Kantian Thomism, asks the puzzling question: can Plotinus within the framework of his monistic ontology really call his own mystical

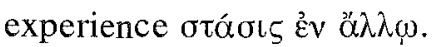

One might ask what exactly does Gardet's and Marechal's question

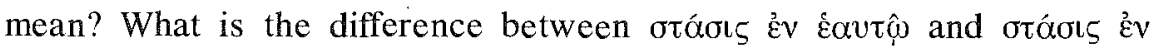
$\alpha \alpha \lambda \lambda \omega$ ? I regard this subtle question as a Gordian knot that is difficult to untie. However, I believe that there is an interesting way of letting the sword cut through the knot.

Alfonso Verdú has pointed out in his study on enstasis and ekstasis (Abstraktion und Intuition als Wege zur Wahrheit in Yoga und Zen, 1965) a special form of mystical experience. Verdú finds it in Zen-buddhism and the Buddhist philosopher Nagarjuna. I believe that it is to be found in Master Eckhart. Verdú calls it genuine ecstasy. I would like to call it an ultimate phase of introvertive mystical experience.

This completely different state that the human consciousness steps into is an absolute void of nothingness experienced in consciousness. When the

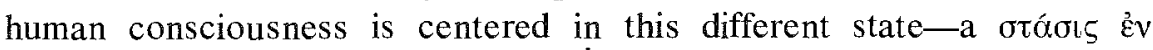
$\alpha \lambda \lambda \omega$-it acquires the ability to hold the two together in a synthesis: the object of introvertive mysticism and the normal reality, the transcendent and the immanent. Characteristic of this kind of transcendence-experience is that it leads beyond the entities with which one labours in the discussion between monistic and dualistic interpretations of mystical experiences. Sometimes this transcendence-experience has been called "transcendence of transcendence" and it is hereby described as the transcending by consciousness of every intentional object, even beyond "void" understood as an intentional object. The experience of absolute void or nothingness is one side of the transcendence-experience. The other side is the effect of nothingness-experience: it permits a synthesis in consciousness between the two opposing aspects of reality: immanent and transcendent, relative and absolute, differentiated and indifferentiated, empiricism's realistic and introvertive mysticism's idealistic view of reality.

When regarded as a psychological phenomenon, this absolute ecstasy is unique. The experience of the expansion of consciousness together with increased intensity and a constant state of pleasure will, of course, remain as a state of consciousness. But a distinct change in relation to the ecstasy of introvertive mysticism is this: the experience of a transcendent reality is 
no longer the over-riding one; instead, the empirical reality is experienced as being the only reality, even if it is, after the experience, regarded as being multidimensional. The three common features of ecstasy-the expansion, of consciousness, intensity and pleasure-complement the features that characterise normal consciousness of the empirical world. To use a metaphorical expression: the three features of ecstasy give a kind of vertical perspective to the normal horizontal understanding of reality.

\section{On the phenomenology of mysticism and ecstasy}

In this paper I have provided answers to the question: what ought one to understand by the phenomena of mysticism and ecstasy and how ought the relationship between them be understood? I regard the approach I have used to find these answers as phenomenological.

But what is phenomenology? Or rather, what is a phenomenological method? As far as I can see, there is no uniformly used paradigm indicating what a phenomenological method should look like? This is also true of the academic discipline called phenomenology of religion.

In this concluding section of my paper, I shall reflect a little on the question: what should a phenomenological method look like, when used to investigate such phenomena as mystical and ecstatic experiences, and how should it be motivated scientifically?

My point of departure is a short summary of Ernst Tugendhat's critique of Edmund Husserl's phenomenological philosophy. (E. Tugendhat: Vorlesungen zur Einführung in die sprachanlytische Philosophie, 1976, p. 92-106.) I shall firstly present Tugendhat's account of three central themes in Husserl's phenomenology:

(1) A fundamental theme in Husserl's philosophy of science is that in order to understand a phenomenon we have to look at a person's consciousness of the phenomenon. Husserl uses the term consciousness in two senses. The first is intentionality. By this, Husserl means that consciousness is always a consciousness or awareness of something. Consciousness is consciousness about something through its activities or intentional acts, such as feeling, thinking and perceiving. The second meaning that Husserl gives to the term "consciousness"' is experience. Husserl gives considerable emphasis to each of these two meanings.

(2) Let us discuss, first of all, consciousness as experience. On it, Husserl constructs the following basic Cartesian tenet: I am certain of that which I experience: I know that I experience this or that. Husserl intends to base the certainty of knowledge on consciousness of a self.

(3) Husserl, however, bases not only the certainty of knowledge but also its essential content on consciousness. In this case, consciousness does not mean experience but intentional act, directed towards an object. 
In order to understand a phenomenon we must comprehend it as the object of an intentional act of consciousness. By reductively excluding everything else and intuitively comprehending the content of the act we gain knowledge of the essence of the phenomenon, i.e., its essential features.

Tugendhat makes the following two objections to these fundamental themes in Husserl's phenomenology:

(1) There is no inner perception of the content of consciousness on which I can base a certainty of knowledge. If there is content in a person's consciousness, can he express it in statements that have meaning and which can be understood by others than himself? Conclusion: we do not need to proceed via consciousness; we may instead confine ourselves to language with regard both to knowledge about experiences and the certainty of this knowledge.

(2) A second objection: the content of intentional acts cannot be understood in any other way than via informative statements. We understand the features of a phenomenon's essence via informative statements and thus we have no need to proceed via intentional acts of consciousness in order to reach them. The assertion that there is a statement in which a person $\mathrm{A}$ asserts the content in an intentional act and thereby asserts a statement $\mathbf{P}$ about the features of a phenomenon can be translated into "A knows that P" which in its turn is equal to the statement "It is true that $\mathrm{P}$ '.

Concerning phenomena and their features, we need not go via consciousness and its experiences or intentional acts; we can and should instead be satisfied with language and an investigation of linguistic statements about phenomena, and of their truth or falsity according to acceptable criteria.

Before I take sides regarding a Husserlian type of phenomenology and Tugendhat's critique of it, I shall mention another kind of critique of phenomenology other than the philosophical one used by Tugendhat. As is well known, Husserl's phenomenology was carried over into Heidegger's existence-philosophy and into different types of existentialism; one type being existential psychology. It has been said that one of the merits of existentialism is its discovery of the role of consciousness in man's experience of what it is to be man. A criticism that has grown increasingly vigorous during the past 20 years with reference to existentialism's view of man is that it loses sight of the human organism. And yet, within the scope of a basic existentialist humanist view of the nature of man, the relationship between consciousness and body has come into focus variously in psychotherapy, psychology and understanding of man in general. I believe that research in this area has something essential to contribute to a phenomenological approach to phenomena that are related to man's consciousness.

In taking sides on the questions of Husserlian phenomenology that I have mentioned, I shall formulate three theses: 
Thesis 1. An empirical method of investigation is to be regarded as phenomenological if, and only if, the investigation takes into consideration the relationship between the phenomenon investigated and human consciousness.

Thesis 2. An investigation whose object is the content of or the product of human consciousness should be formulated as a phenomenological investigation.

Thesis 3. The result of a consciousness-directed phenomenological investigation ought to be adequately tested with the help of linguistic analytical philosophy and body-directed psychology.

By consciousness-directed phenomenology I mean a phenomenology which fulfills the demand stated in thesis 1 . By a linguistic analytical philosophy I mean a philosophy which studies the philosophical problems concerning knowledge and ontology via linguistic assertions. By a bodydirected psychology I mean a psychology which studies man's psychological processes in relation to their bodily conditions.

The way in which an interaction between phenomenology, philosophy and psychology according to thesis 3 can and should function can be exemplified with the help of the following example. The example I choose is the phenomenon that I have called ecstasy in an absolute sense.

(1) Concerning the necessity of a phenomenological approach in an investigation of consciousness-related phenomena

Absolute ecstasy means, as we saw, the experience of a state of consciousness which, it is claimed, is able to cause experience of a synthesis of a transcendent and a non-transcendent dimension of reality. It is easy to realise that a necessary condition for an understanding of statements claiming experience of a synthesis between transcendence and immanence is the psychological understanding of the state of consciousness in which the claimed experience of the synthesis was made. It is only in the context of a psychological understanding of the state of consciousness which is called absolute nothingness that the mystics' claims of a synthesis or an integrated unity of empirical reality and what transcends it becomes meaningful.

(2) Concerning the desirability of correlating the psychological study of a consciousness-related phenomenon with a study of the phenomenon's bodily conditions

Of course, the indication of a correlation between an alleged state of consciousness of absolute nothingness, a state in which it is supposedly possible to experience a synthesis of immanence and transcendence with empirically established states of the body, has relevance for the understanding of the phenomenon of absolute ecstasy. By establishing such a correlation, one can place the experience of nothingness in a psychological 
context which is intersubjectively controllable and, thereby, grant the experience an objective status.

\section{(3) Concerning the linguistic-analytical task}

By indicating the nothingness-experience's facticity one has of course not said anything about the objective knowledge value of the assertion of an experienced synthesis between transcendence and immanence. The meaning of this assertion, its reference and epistemological status can only be defined through a philosophical analysis of the assertion itself. But even if the investigation in itself is linguistic-analytical it presumably needs support from research into of the genesis of the understanding being expressed in the assertion. The linguistic-analytical investigation will "hang in the air" if it is made without consideration of what a consciousness-directed phenomenological and a body-directed psychological investigation have to offer.

I regard my reasoning as an argument for my three theses. With them I opt for a revised version of Husaserl's phenomenological method, and against Tugendhat's critique of Husserl, I wish to claim that consciousnessrelated phenomena-such as mysticism and ecstasy-cannot be understood except by understanding the states and intentional acts of consciousness in which these phenomena are given. 